\title{
PRÉ-MELHORAMENTO DE MILHO PARA RESISTÊNCIA À MANCHA-BRANCA E À FERRUGEM-POLISSORA
}

\section{FLAVIA FRANÇA TEIXEIRA ${ }^{1}$, ARLEY FIQUEIREDO PORTUGAL ${ }^{1}$, MARCIELE SILVA OLIVEIRA ${ }^{1}$, DAGMA DIONÍSIA DA SILVA ${ }^{1}$, LAURO JOSÉ MOREIRA GUIMARÃES ${ }^{1}$, PAULO EVARISTO DE OLIVEIRA GUIMARÃES ${ }^{1}$ e SIDNEY NETTO PARENTONI ${ }^{1}$}

\author{
${ }^{1}$ Embrapa Milho e Sorgo, Rod MG 424 km 35, Sete Lagoas, CEP 35701-970, flavia.teixeira@embrapa.br, \\ arley.portugal@embrapa.br,marcieleol@yahoo.com.br,dagma.silva@embrapa.br,lauro.guimaraes@embrapa.br, \\ paulo.guimaraes@embrapa.br,sidney.parentoni@embrapa.br
}

Revista Brasileira de Milho e Sorgo, v.16, n.2, p. 273-286, 2017

\begin{abstract}
RESUMO - O Banco Ativo de Germoplasma de Milho (BAGMilho) preservado na Embrapa Milho e Sorgo mantém cerca de 4.000 variedades. Entretanto, essas variedades não têm o padrão agronômico das cultivares comerciais, o que reduz o seu potencial do uso direto. O pré-melhoramento possibilita o desenvolvimento de genótipos com maior potencial de uso por meio da hibridização entre acessos do BAGMilho e genótipos melhorados. O objetivo deste trabalho foi avaliar famílias endogâmicas obtidas de cruzamentos entre linhagens-elite e os acessos do BAGMilho composto-fonte de resistência à mancha-branca e composto-fonte de resistência à ferrugem-polissora quanto à reação a patógenos, produtividade e caracteres agronômicos. Famílias endogâmicas derivadas de retrocruzamentos entre estes compostosfonte de resistência e linhagens-elite foram avaliadas em cruzamentos com testadores dos grupos heteróticos duro e dentado. Os ensaios foram conduzidos em Sete Lagoas e Nova Porteirinha em duas épocas de semeadura. Os resultados permitiram selecionar as famílias endogâmicas MB130, MB181, MB164, FP109, FP133, FP104, FP120, FP112, FP103 e FP140 para uso em cruzamentos com linhagens do grupo heterótico duro e as famílias endogâmicas MB024, MB032, MB083, FP028, FP036 e FP020 para uso em cruzamentos com linhagens do grupo heterótico dentado.
\end{abstract}

Palavras-chave: recursos genéticos, fitopatologia, Zea mays, Pantoea ananatis, Puccinia polysora.

\section{MAIZE PRE-BREDING FOR RESISTANCE TO WHITE SPOT AND POLYSORA RUST}

\begin{abstract}
The Maize Active Germplasm Bank (GBMaize) preserves about 4,000 varieties of maize. However, these varieties do not have the standard commercial performance that reduces their potential of agricultural use. Pre -breeding enables the development of greater agricultural use of genotypes by hybridization between the accessions from GBMaize and improved genotypes. The aim of this study was to evaluate inbred families obtained from crosses between inbred lines and accessions of GBMaize called source of resistance to white spot composite and source of resistance to polysora rust composite in crosses for resistance to pathogens, grain yield and agronomic traits. Inbred families derived from crosses between inbred lines and source of resistance to white spot and source of resistance to polysora rust composites were evaluated in crosses with flint and dent heterotic patterns testers. The trials were conducted in Sete Lagoas and Nova Porteirinha in two sowing dates for the evaluation of resistance to pathogens, yield and traits of agronomic importance. The results allowed select inbred families MB130, MB181, MB164, FP109, FP133, FP104, FP120, FP112, FP103 and FP140 for use in crosses with flint heterotic pattern and inbred families MB024, MB032, MB083, FP028, FP036 and FP020 for use in crosses with dent heterotic pattern.
\end{abstract}

Keywords: renetic resources, phytopathology, Zea mays, Pantoea ananatis, Puccinia polysora. 
O Banco Ativo de Germoplasma de Milho (BAGMilho) mantido na Embrapa Milho e Sorgo preserva cerca de 4.000 acessos que são, em sua maioria, variedades coletadas em diversas regiões brasileiras entre as décadas de 1950 e 1980. Esses genótipos contrastam com as cultivares de milho presentes nas lavouras brasileiras atualmente, que são, em geral, cultivares de alta performance disponibilizadas por programas de melhoramento. Esse panorama faz com que as variedades preservadas pelo BAGMilho não tenham o padrão agronômico das cultivares comerciais atuais, impedindo seu uso direto. Não obstante, o BAGMilho mantém a diversidade genética da cultura, o que torna essa coleção de grande potencial de uso na busca de soluções para as mais diversas demandas agrícolas.

A manutenção do BAGMilho engloba uma série de atividades, entre elas: introdução, intercâmbio, conservação, regeneração/multiplicação, caracterização, avaliação e informatização dos dados (Teixeira et al., 2011). Dentre essas atividades, a caracterização e a avaliação agregam valor ao BAG Milho. O uso de acessos do BAG no melhoramento é baixo e a agregação de valor contribui para aumentar o potencial de uso do BAGMilho em programas de melhoramento. Algumas das razões para o baixo uso do BAG Milho foram listadas por Nass et al. (2007) e, dentre elas, destacam-se a falta de documentação e descrição adequada das coleções de germoplasma; falta de informações úteis sob o ponto de vista do melhoramento; satisfação dos melhoristas com a variabilidade genética encontrada nos materiais elite; dificuldade de identificar genes potencialmente úteis e ausência de programas de pré-melhoramento.

A maioria dos estudos em pré-melhoramento no Brasil consideraram a avaliação de acessos per se.
Dentre esses estudos, já foram enfocadas a adaptação às condições ambientais especificas, tal como as condições de estresse de seca (Teixeira et al., 2010) e aos estresses bióticos (Miranda Filho et al., 2000; Teixeira, et al., 2013). Miranda Filho et al. (2000) avaliaram mais de 1.000 acessos do BAGMilho quanto à tolerância a cinco patógenos e também desenvolveram cinco compostos-fontes de resistência a patógenos. Um destes compostos, denominado NAP enfezamento, ou seja, um composto obtido a partir de fontes de resistência ao enfezamento, foi hibridizado com linhagens-elites do programa de melhoramento da Embrapa Milho e Sorgo visando a avaliação de genótipos derivados do composto em cruzamentos e a comparação de metodologias de seleção (Teixeira et al., 2013).

Uma das principais doenças foliares do milho no Brasil é a mancha-branca (Pantoea ananatis) (Paccola-Meirelles et al., 2001), cujos sintomas na fase inicial de desenvolvimento da doença são caracterizados por lesões circulares, aquosas e verde-claras em folhas inferiores. Posteriormente, as lesões progridem para a parte superior das folhas e as lesões se tornam necróticas, de coloração palha e formato circular e elíptico (Costa et al., 2010a). Os plantios tardios de milho favorecem condições ambientais para o rápido desenvolvimento da doença.

Em cultivares suscetíveis, a mancha-branca pode reduzir a produção de grãos em até $60 \%$ e reduzir a taxa fotossintética líquida em $40 \%$ quando as folhas apresentam de 10-20\% de severidade, o que resulta queda na produção (Godoy et al., 2001). O uso de cultivares resistentes é a forma de controle mais efetiva do ponto de vista prático, econômico e ambiental, entretanto nem sempre tem sido consistente, o que leva à necessidade da aplicação de defensivos químicos que são indicados para o controle da mancha-branca 
em milho. Contudo, segundo Pereira Filho e Borghi (2016), apenas 9\% das cultivares recomendadas para a safra 2016-2017 são classificadas como resistentes à mancha-branca. Costa e Cota (2009) indicam que o uso de defensivos químicos deve ser racional, tendo em vista os menores riscos à saúde humana e ao meio ambiente, o menor custo de produção e a preservação da efetividade das moléculas fúngicas em razão do menor surgimento de populações de patógenos resistentes.

Outra importante doença em milho no Brasil é a ferrugem-polissora (Puccinia polysora Underw). A ferrugem-polissora é capaz de reduzir em mais de $50 \%$ a produtividade da cultura do milho, sendo seus danos causados pela redução de área foliar, vigor, massa de grãos e por senescência precoce das plantas. Os sintomas dessa doença são formação de pústulas circulares a ovais, de coloração marrom-clara, distribuídas, predominantemente na face superior das folhas. A resistência genética também é uma das principais estratégias de manejo dessa ferrugem (Pataky et al., 2000; Casela \& Ferreira, 2002; Costa et al., 2010b). Entretanto, segundo Pereira Filho e Borghi (2016), apenas 17\% das cultivares recomendadas para a safra 2016-2017 são classificadas como resistentes à ferrugem-polissora.

Assim, tanto para a mancha-branca quanto para a ferrugem-polissora, a busca por novas fontes que possam ser utilizadas em programas de melhoramento é importante para a ampliação de base genética da cultura do milho. O objetivo desse trabalho foi avaliar famílias endogâmicas obtidas de cruzamentos entre linhagens-elites e os compostos-fonte de resistência à mancha-branca e fonte de resistência à ferrugem-polissora, em cruzamentos com linhagens testadoras quanto à reação aos patógenos, produtividade de grãos e caracteres agronômicos.

\section{Material e Métodos}

Nesse trabalho, foram avaliados dois grupos de famílias endogâmicas, o primeiro deles (grupo MB) foi derivado de cruzamentos com o composto-fonte de tolerância à mancha-branca $(\mathrm{CMB})$ e o segundo grupo de genótipos (grupo FP) foi derivado de cruzamentos com o composto-fonte de tolerância à ferrugem-polissora (CFP). Ambos os compostos foram desenvolvidos por Miranda Filho et al. (2000) a partir de acessos disponíveis no BAGMilho.

As famílias endogâmicas do grupo $\mathrm{MB}$ foram 53 genótipos derivados de retrocruzamentos (RC) entre o composto-fonte de tolerância à mancha-branca (genitor doador CMB) e duas linhagens-elites do Programa de Melhoramento de Milho da Embrapa Milho e Sorgo, como genitores recorrentes, sendo uma do grupo heterótico duro, registrada no Ministério da Agricultura, Pecuária e Abastecimento (Mapa) como CMS M027 e abreviada no presente trabalho como LF, e a outra, do grupo heterótico dentado, registrada no Mapa como CMS M019 e abreviada no presente trabalho como LD. Assim, as famílias endogâmicas do grupo MB têm em média $75 \%$ do germoplasma -elite, uma vez que foram derivadas de $\mathrm{RC}_{1}$. Após o RC, as populações foram conduzidas para campo, onde foi feita seleção com base na avaliação fenotípica da reação ao patógeno e autofecundação das plantas selecionadas. Essas famílias foram identificadas pelas letras "MB" seguidas da numeração sequencial.

As famílias endogâmicas do grupo FP foram 78 genótipos derivados de cruzamentos entre o composto-fonte de tolerância à ferrugem-polissora (genitor doador CFP), e, como genitores recorrentes, as duas linhagens-elites do Programa de Melhoramento de Milho da Embrapa Milho e Sorgo LF e LD, descritas acima. As famílias endogâmicas do grupo FP 
têm $50 \%$ do germoplasma-elite, uma vez que essas famílias foram derivadas da geração $F_{1}$. Após o cruzamento, as populações foram conduzidas para campo para a autofecundação. Essas famílias foram identificadas pelas letras "FP" seguidas da numeração sequencial.

Os genótipos dos grupos MB e FP foram testados em cruzamentos, para tanto, foram obtidos híbridos experimentais por meio do cruzamento entre as famílias endogâmicas e duas linhagens testadoras, a saber: CMS M027, que foi cruzada com genótipos de grão dentado, e CMS M019, que foi cruzada com genótipos de grão duro. Desta forma, os tratamentos do grupo MB foram 53 híbridos experimentais, e como testemunhas foram o acesso do BAGMilho composto-fonte de tolerância à mancha-branca $(\mathrm{CMB})$ e os híbridos BRS1030 e BRS1035. Já no grupo FP, os tratamentos foram 78 híbridos experimentais, e a testemunha foi o composto-fonte de tolerância à ferrugem-polissora (CFP) e o híbrido BRS1035.

Cada grupo foi avaliado em dois locais (Sete Lagoas e Nova Porteirinha, ambos em Minas Gerais) e duas épocas de plantio (janeiro e abril de 2011), totalizando quatro condições ambientais. As condições ambientais dos locais e épocas onde foram conduzidos os ensaios são apresentados na Tabela 1. Utilizouse o delineamento de blocos casualizados com três repetições. As parcelas experimentais foram compostas de uma linha de $5 \mathrm{~m}$, com espaçamento entre linhas de $70 \mathrm{~cm}$ e densidade de semeadura de 5 plantas por metro linear. Os grupos MB e FP foram avaliados em ensaios distintos, mas alocados lado a lado. A inoculação de plantas foi natural. Os tratos culturais foram os usuais da cultura do milho, exceto pela supressão do controle químico de patógenos. Os ensaios contaram com irrigação suplementar quando necessário. Foram avaliados os seguintes caracteres:
- Florescimento feminino (FF): tomado pela diferença em dias entre a emergência das plântulas e a emissão do estilo-estigma em, pelo menos, 50\% das plantas da parcela.

- Altura de espiga (AE): medida, em cm, do solo até a inserção da primeira espiga.

- Índice de plantas acamadas ou quebradas (ACQ): calculado pela divisão do número de plantas acamadas ou quebradas pelo número total de plantas da parcela.

- Prolificidade (PROL): calculada pelo número de espigas da parcela dividido pelo número total de plantas na parcela.

- Produtividade de grãos (PG): tomada pela massa total de grãos produzidos na parcela, com a padronização da umidade dos grãos para 13\%, e apresentada em $t$ ha-1.

- Incidência de sintomas do patógeno nos ensaios do grupo MB foi avaliada por meio de escala de notas, variando de 1 a 5 , considerando o percentual de área foliar tomada por lesões caudadas pela mancha-branca (NMB), sendo a nota "1" atribuída para parcelas nas quais o percentual da área foliar tomada por lesões foi inferior a $1 \%$, nota " 2 " atribuída para parcelas nas quais o percentual da área foliar tomada por lesões foi entre 1 e 10\%, nota " 3 " atribuída para parcelas nas quais o percentual da área foliar tomada por lesões foi entre 10 e $30 \%$, nota “ 4 ” atribuída para parcelas nas quais o percentual da área foliar tomada por lesões foi entre 30 e $60 \%$, e nota "5", para parcelas com mais de $60 \%$ da área foliar afetada pelas lesões (adaptado de Brito et al., 2011).

- Incidência de sintomas do patógeno nos ensaios do grupo FB foi avaliada por meio de escala de notas, variando de 1 a 4, de acordo a observação das lesões foliares causadas pela ferrugem-polissora (NFP), sendo a nota "1" atribuída para parcelas com 
Tabela 1. Precipitação (Prec) $(\mathrm{mm})$, temperatura média $(\mathrm{TM})\left({ }^{\circ} \mathrm{C}\right)$ e umidade relativa do ar média (UR) $(\%)$ nos locais e meses de condução dos ensaios.

\begin{tabular}{|c|c|c|c|c|c|c|c|}
\hline \multirow{2}{*}{$\begin{array}{l}\text { Local } \\
\text { Sete Lagoas }\end{array}$} & & \multicolumn{6}{|c|}{ Meses de condução dos ensaios (2011) } \\
\hline & & Janeiro & Fevereiro & Março & Abril & Maio & Junho \\
\hline \multirow[t]{4}{*}{ Época $1^{1}$} & Prec & 163,6 & 233,0 & 354,6 & 15,3 & 0,9 & 5,4 \\
\hline & TM & 23,8 & 24,8 & 23,1 & 22,5 & $-{ }^{2}$ & 18,8 \\
\hline & UR & 72,0 & 62,5 & 78,2 & 70,7 & 65,8 & 66,6 \\
\hline & & Abril & Maio & Junho & Julho & Agosto & Setembro \\
\hline \multirow[t]{3}{*}{ Época 2} & Prec & 15,3 & 0,9 & 5,4 & 0,0 & 0,0 & 0,0 \\
\hline & TM & 22,5 & - & 18,8 & 18,2 & 21,2 & 21,9 \\
\hline & UR & 70,7 & 65,8 & 66,6 & 59,4 & 49,6 & 46,5 \\
\hline Janauba $^{3}$ & & Janeiro & Fevereiro & Março & Abril & Maio & Junho \\
\hline \multirow{4}{*}{ Época 1} & Prec & 90,6 & 42,9 & 166,8 & 8,4 & 1,3 & 0,0 \\
\hline & $\mathrm{TM}$ & 25,5 & 26,9 & 24,9 & 25,4 & 23,7 & 22,8 \\
\hline & UR & 67,9 & 57,6 & 77,4 & 63,6 & 58,7 & 55,6 \\
\hline & & Abril & Maio & Junho & Julho & Agosto & Setembro \\
\hline \multirow[t]{3}{*}{ Época 2} & Prec & 8,4 & 1,3 & 0,0 & 0,0 & 0,0 & 0,6 \\
\hline & $\mathrm{TM}$ & 25,4 & 23,7 & 22,8 & 22,4 & 24,0 & 24,5 \\
\hline & UR & 63,6 & 58,7 & 55,6 & 51,0 & 46,6 & 39,6 \\
\hline
\end{tabular}

${ }^{1}$ Datas de plantio da época 1: 19 e 24 de janeiro de 2011 em Nova Porteirinha e Sete Lagoas, respectivamente. Datas de plantio da época 2: 4 e 13 de abril de 2011 em Sete Lagoas e Nova Porteirinha, respectivamente.

${ }^{2}$ Dado não disponibilizado

${ }^{3}$ Dados ambientais da estação do INMET de Janaúba-MG, que é município vizinho e contíguo ao de Nova Porteirinha, onde foram conduzidos os ensaios.

Fonte: Instituto Nacional de Meteorologia (INMET) - (http://www.inmet.gov.br/projetos/rede/pesquisa/inicio.php)

ausência total de reação nas folhas, nota "2" atribuída para parcelas que apresentam folhas com mancha cloróticas a necróticas sem a formação de urédias, nota " 3 " atribuída a parcelas com folhas apresentando poucas urédias formadas com pequenas quantidades de uredósporos, e nota " 4 " atribuída a parcelas com folhas apresentado grande quantidade de urédias com ou sem clorose ou amarelecimento contendo abundante quantidade de uredósporo (Costa et al., 2011).

Após a tomada de dados foi realizada a análise de variância conjunta e, de acordo com os resultados dessa análise, foram feitos os agrupamentos das médias seguindo a metodologia de Scott-Knott. O programa GENES (Cruz, 2013) foi empregado para as análises de variância e testes de médias e para a cor- reção do estande utilizando a metodologia do estande ideal.

\section{Resultados e Discussão}

Os resultados das análises de variância dos tratamentos avaliados no grupo MB são apresentados na Tabela 2. Não foram observados sintomas de mancha -branca nas avaliações conduzidas em Nova Porteirinha, portanto, para fins de seleção, considerando esse caráter, foram empregadas apenas as avaliações em Sete Lagoas.

A precisão experimental foi considerada alta (Fritche-Neto et al., 2012), tendo em vista a estimativa de coeficiente de variação para produtividade 


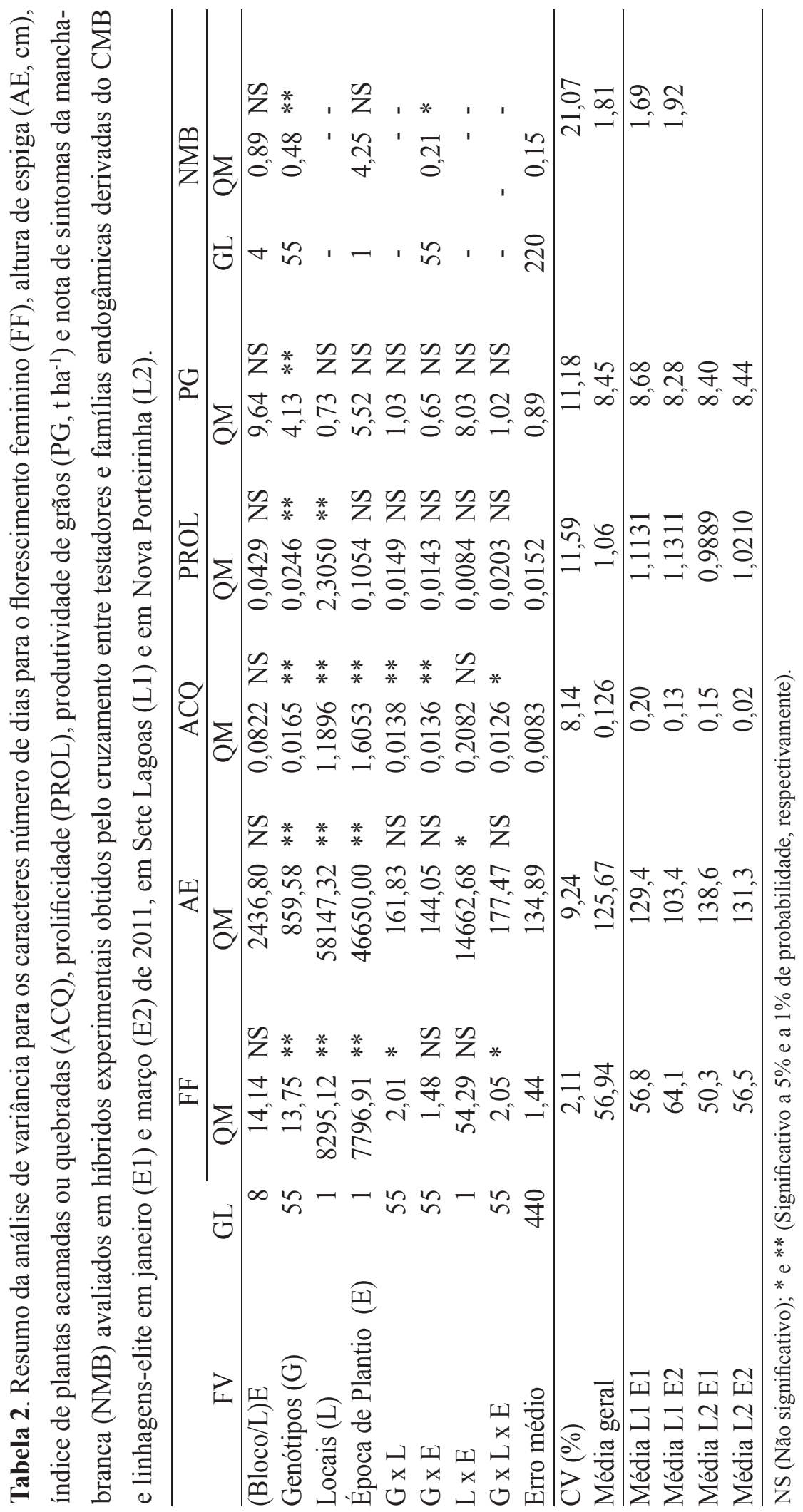


de grãos variando entre 10,18 e 19,73\% e com valor médio de $11,18 \%$. Os genótipos avaliados diferiram para todos os caracteres e houve efeito significativo dos locais e épocas de plantio para a maioria dos caracteres. As interações genótipos por locais e genótipos por épocas de plantio estiveram ausentes para a maioria dos caracteres, estando presente, com alta significância, apenas para índice de plantas acamadas ou quebradas e para a interação entre genótipos e locais para florescimento feminino. Na Tabela 2, são apresentadas também as médias gerais do ensaio e em cada ambiente, sendo possível notar que da primeira para a segunda época de plantio houve atraso no número de dias para florescimento feminino, redução na altura de espigas e no índice de plantas quebradas e acamadas e aumento na incidência dos sintomas da mancha-branca. Quando comparadas as médias das avaliações em Sete Lagoas às de Nova Porteirinha, é possível notar que em Sete Lagoas o florescimento feminino foi mais tardio, a altura de espigas foi menor e que o índice de plantas acamadas ou quebradas e a prolificidade foram maiores.

Deve ser destacado também que, em média, a incidência de sintomas do patógeno foi baixa (notas com valor médio de 1,81; moda, 2 e médias com intervalo de 1,25 a 2,33), o que possivelmente tenha ocorrido por contribuição do genitor doador, entretanto deve ser ressaltado que mesmo havendo baixa incidência dos sintomas da mancha-branca foi possível identificar diferenças entre genótipos. Embora os plantios tardios de milho favoreçam condições ambientais para o rápido desenvolvimento da doença (Costa et al., 2011), a ausência da interação entre a nota dos sintomas da mancha-branca e épocas de plantio sugeriu que essa avaliação apresenta resultados semelhantes entre épocas de semeadura, ou seja, independentemente de a pressão do patógeno ser maior no plantio tardio, os níveis de resistência dos genótipos não variaram. Já a escolha do local para a avaliação foi fundamental para a identificação da reação ao patógeno.

A seleção dos genótipos de melhor desempenho foi feita considerando-se os caracteres principais para esse estudo, ou seja, a produtividade de grãos e a nota de incidência da mancha-branca. Já os demais caracteres não foram usados para a seleção dos genótipos de desempenho superior, assim, apenas a média geral foi considerada. Na Tabela 3, são apresentadas as médias dos genótipos de maior produtividade de grãos e das testemunhas. Os genótipos selecionados, por causa do melhor desempenho, foram grifados em cinza. Com base no critério estabelecido, apenas seis híbridos experimentais $(11 \%$ do total de genótipos testados) foram selecionados. Quando considerados o desempenho dos genótipos selecionados em combinação com os grupos heteróticos explorados pelo melhoramento de milho no Brasil (Parentoni et al., 2001; Santos et al., 2001), foi observado que as famílias endogâmicas MB130, MB181 e MB164 apresentam potencial de uso no melhoramento em cruzamentos com linhagens do grupo heterótico duro, e que as famílias endogâmicas MB024, MB032 e MB083 apresentam potencial de uso no melhoramento em cruzamentos com linhagens do grupo heterótico dentado. Outra observação que merece destaque é a maior PG dos materiais selecionados em relação aos híbridos simples BRS 1030 e BRS 1035. Entretanto deve ser feita a ressalva de que o baixo desempenho do híbrido BRS 1035, mesmo após a correção do estande, pode ter sido causado por baixo vigor de sementes. As notas de incidência da mancha-branca destes genótipos obtidas na primeira época de plantio chegaram a ser mais favoráveis que a testemunha $\mathrm{CMB}$, considerada como resistente. Esses resultados mostram o eleva- 
do potencial de obtenção de genótipos superiores por meio de programas de melhoramento que envolvam cruzamentos entre acessos do BAG Milho e linhagens-elite.

Os resultados das análises de variância dos tratamentos avaliados no grupo FP são apresentados na Tabela 4. Não foram observados sintomas de ferrugem-polissora nas avaliações conduzidas em Sete Lagoas, portanto, para fins de seleção visando esse caráter foram empregadas apenas as avaliações em Nova Porteirinha.

A precisão experimental foi considerada alta (Fritche-Neto et al., 2012), tendo em vista que a estimativa do coeficiente de variação para produtividade de grãos variou entre 8,99 e 15,55\% com valor médio de $12,21 \%$. Os genótipos avaliados diferiram para todos os caracteres, exceto incidência de ferrugem-polissora e houve o efeito significativo dos locais e das épocas para a maioria dos caracteres. A interação genótipos por ambientes esteve presente, com alta significância, entre genótipos e locais para os caracteres florescimento feminino, altura de espiga e produtividade de grãos e entre genótipos e épocas de plantio para a produtividade de grãos. Ao serem comparadas as médias gerais de cada ambiente, é possível notar que em Sete Lagoas o número de dias para florescimento feminino foi menor e a altura de espigas e o índice de acamamento foram maiores do que em Nova Porteirinha. Em média, na primeira época de plantio, foram obtidos maiores número de dias para florescimento feminino e índice de acamamento ou quebramento e menor altura de espigas do que na segunda época de plantio. Assim como na avaliação do grupo MB, deve ser destacado também que, em média, a incidência de sintomas do patógeno foi baixa (notas com valor médio de 1,39; moda, 1 e dentro do intervalo de 1,17 a 1,60), o que corresponde a baixo percentual da área foliar tomada pelas lesões características da ferrugem-polissora, o que possivelmente tenha sido conferido pelo genitor doador e que levou à não diferenciação dos tratamentos quanto a reação ao patógeno. Apesar de os genótipos testados terem manifestado bom nível de resistência, outras avaliações são indicadas para que eles prossigam em programas de melhoramento para o desenvolvimento de genótipos resistentes à ferrugem-polissora. É oportuno ressaltar também que em média a incidência de ferrugem-polissora foi mais elevada na primeira época de plantio do que na segunda, o que sugere que a semeadura em janeiro foi mais favorável à expressão da resistência ao patógeno.

As médias e os resultados dos testes de médias das testemunhas e de 30 genótipos que foram classificados pelo teste de médias como os de maior produtividade de grãos nas quatro condições ambientais são apresentados na Tabela 5. Nessa Tabela, foram grifadas de cinza as médias classificadas como favoráveis. Como critério de seleção, foi considerada não apenas a produtividade de grãos, mas também o desempenho superior em pelo menos dois dos seguintes caracteres: número de dias de florescimento feminino, altura de espiga e índice de plantas acamadas ou quebradas. Desta forma, foram selecionados 10 tratamentos (grifados de cinza), o que corresponde a $12,7 \%$ do total de materiais avaliados. De acordo com a combinação dos materiais selecionados com as linhagens representantes dos grupos heteróticos utilizados no melhoramento (Parentoni et al., 2001; Santos et al., 2001), foi possível indicar que as famílias endogâmicas FP109, FP133, FP104, FP120, FP112, FP103 e FP140 apresentaram potencial de uso no melhoramento em combinação com linhagens do grupo heterótico duro e as famílias endogâmicas FP028, FP036 e FP020, com linhagens do grupo heterótico dentado. Quanto 


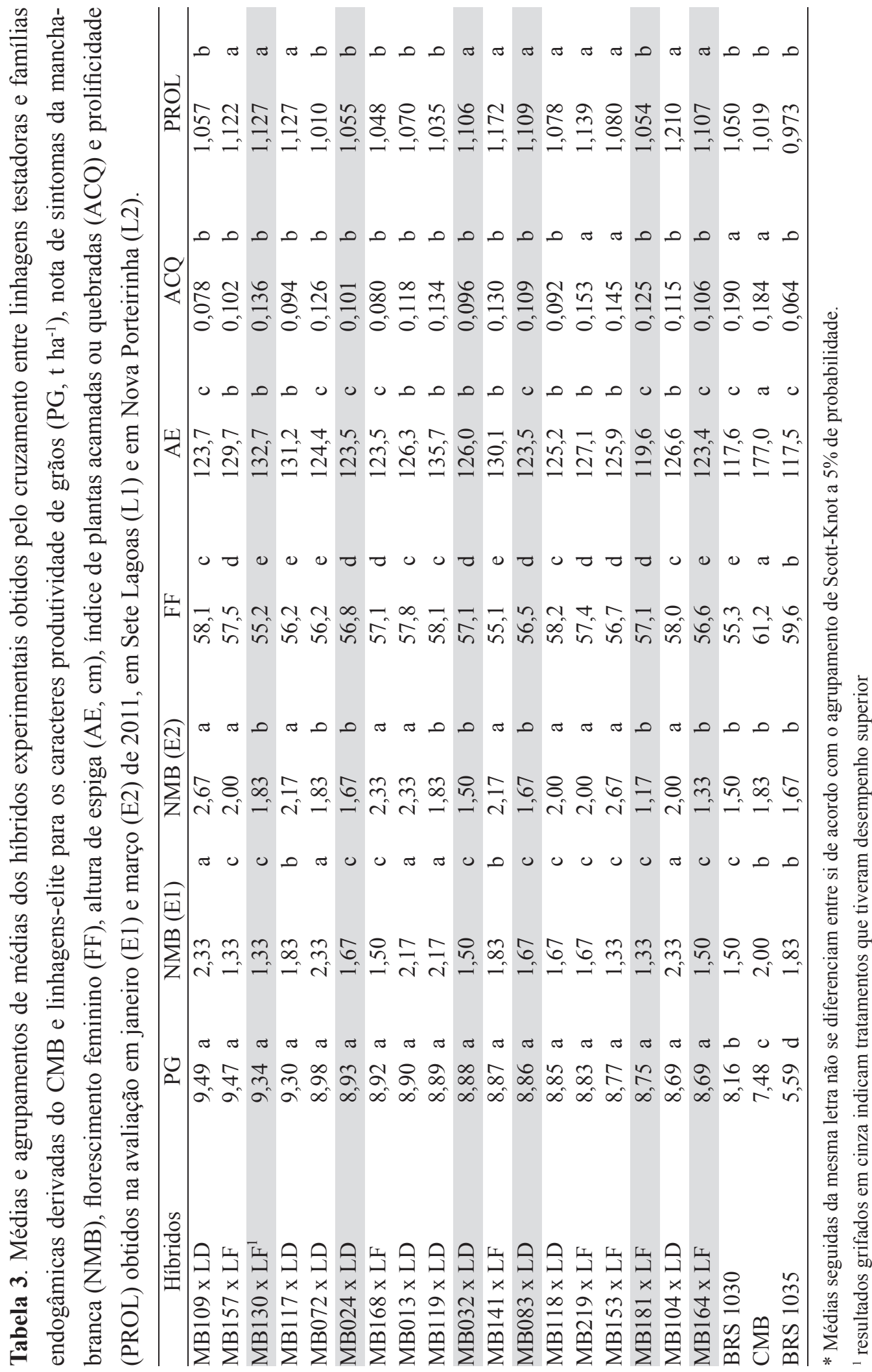




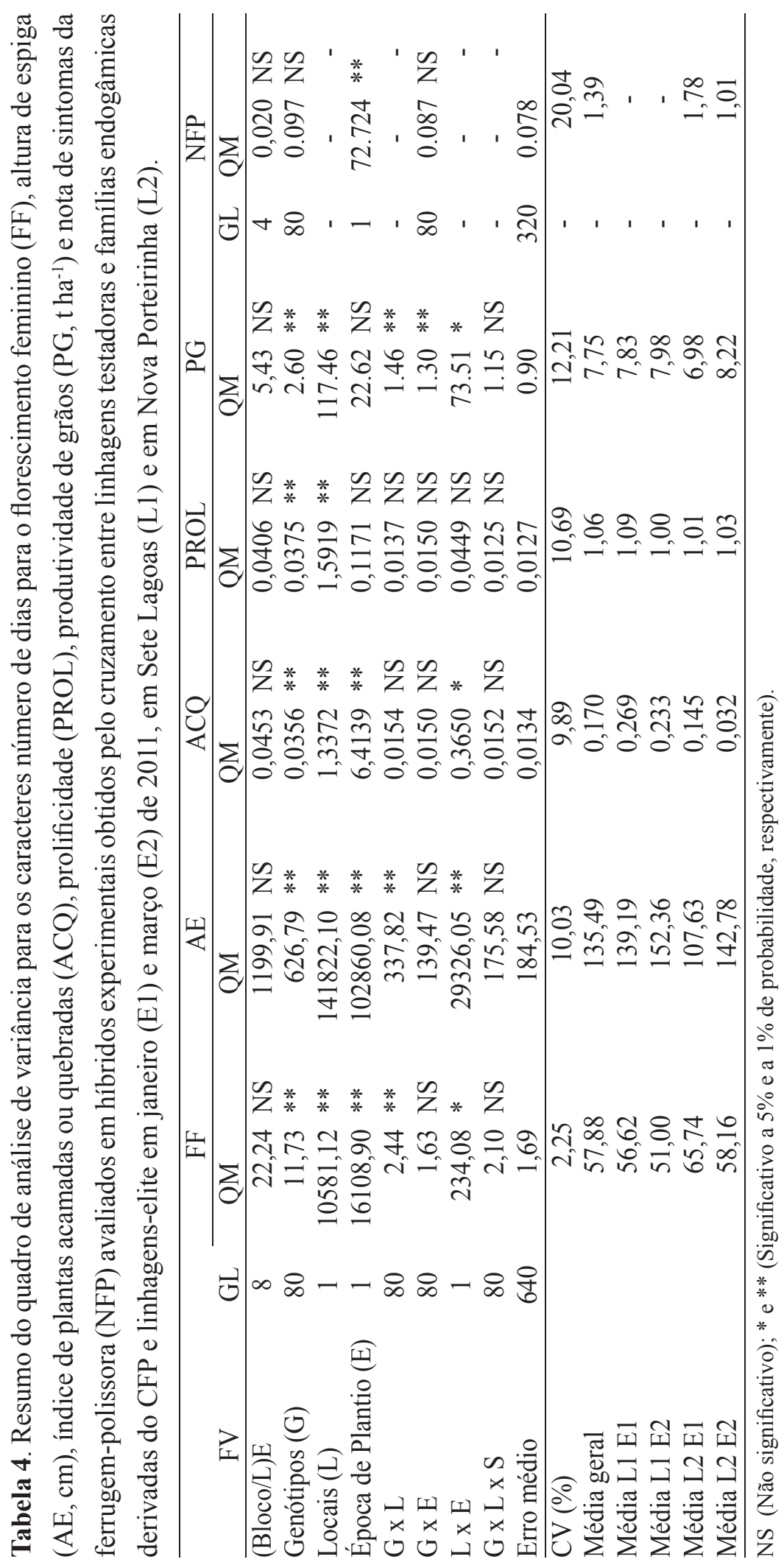


ao desempenho das testemunhas, é possível notar que o híbrido simples BRS 1035 apresentou produtividade de grãos em Nova Porteirinha abaixo do patamar atingido pelos materiais mais produtivos desse ensaio, o que não era esperado. Entretanto, assim como no ensaio do grupo MB, é possível que, mesmo após a correção do estande, o baixo desempenho do BRS 1035 tenha sido causado por baixo vigor de sementes. Era esperado que o CFP apresentasse baixa produtividade, por ser um composto formado por genótipos não melhorados, entretanto esse composto apresentou boa produtividade de grãos em alguns ambientes, chegando a atingir a produtividade de grãos de 8,36 $\mathrm{t} \mathrm{ha}^{-1}$ em Janaúba na avaliação com semeadura em março de 2011, porém apresentou desempenhos de florescimento feminino, altura de planta e índice de plantas acamadas ou quebradas desfavoráveis.

A condução dos ensaios levou à observação de outros aspectos, além do objetivo principal do trabalho, que foi a seleção de genótipos superiores. Entre esses aspectos, está a confirmação do potencial dos compostos CMB e CFP como genitores fontes para a resistência para mancha-branca e ferrugem-polissora, respectivamente. Entretanto, apesar destes compostos terem alto valor para o melhoramento, eles vêm sendo subutilizados, uma vez que até o presente momento apenas outro composto obtido por Miranda Filho et al. (2000), o composto fonte de tolerância ao enfezamento, havia sido empregado no pré-melhoramento (Teixeira et al., 2013). Assim, foi confirmado o potencial do emprego desses compostos para introgressão em linhagens-elite, uma vez que foi possível obter genótipos com níveis de resistência superior ao genitor doador, o que reforça a importância de ações de pesquisa que promovam o uso do banco de germoplasma e em pré-melhoramento (Nass et al., 2007).
As avaliações já conduzidas visando agregar valor ao BAG Milho consideraram, em sua maioria, o desempenho dos acessos per se (Miranda Filho et al., 2000; Andrade et al., 2002; Teixeira et al., 2002, 2010). Entretanto, tendo em vista o enfoque dos programas de melhoramento na obtenção de híbridos e sintéticos, faz-se necessária a avaliação de acessos do BAG Milho em cruzamentos com linhagens representantes dos principais grupos heteróticos (Teixeira et al., 2013). A introgressão e a classificação de genótipos em fase de pré-melhoramento nos grupos heteróticos aumentam o potencial de extração de genótipos de alto valor do BAG Milho.

Os percentuais de germoplasma-elite e não melhorado indicados a serem usados em programas de pré-melhoramento são variáveis e foram revistos por Nass e Paterniani (2000). Os autores citam que já foram encontrados resultados favoráveis com o uso de apenas $25 \%$ de germoplasma não adaptado, o que corresponde a uma geração de retrocruzamento, e também com o uso de $50 \%$ de germoplasma não adaptado, o que é obtido com a $F_{1}$ entre o cruzamento entre o pai doador e recorrente. A geração ideal para a introgressão foi avaliada em estudo de simulação por Gorjanc et al. (2016), que sugerem que a introgressão deve ser feita em fases iniciais do programa de pré-melhoramento quando o objetivo é alelos que condicionam características controladas por menor número de genes. No presente trabalho, as famílias endogâmicas do grupo MB têm em média $75 \%$ do germoplasma-elite, já as do grupo FP têm 50\%, uma vez que essas famílias foram derivadas de $\mathrm{RC}$ e de F1, respectivamente. A comparação entre o desempenho médios desses dois grupos de genótipos envolve alguns fatores divergentes, entre eles, o pai doador e o percentual de introgressão, entretanto outros fatores são comuns nos dois grupos de ensaios, tais como as 
Tabela 5. Médias e agrupamentos de médias dos híbridos experimentais obtidos pelo cruzamento entre linhagens testadoras e famílias endogâmicas derivadas do CFP e linhagens-elite para os caracteres produtividade de grãos ( $\left.\mathrm{PG}, \mathrm{t} \mathrm{ha}^{-1}\right)$ em cada ambiente e florescimento feminino (FF), altura de espiga (AE, $\mathrm{cm}$ ), índice de plantas acamadas ou quebradas (ACQ) e prolificidade (PROL) obtidos na avaliação em janeiro (E1) e março (E2) de 2011, em Sete Lagoas (L1) e em Nova Porteirinha (L2).

\begin{tabular}{|c|c|c|c|c|c|c|c|c|c|c|c|c|c|c|c|c|}
\hline Híbridos & $\begin{array}{c}\text { PG } \\
\text { E1L1 }\end{array}$ & & $\begin{array}{c}\mathrm{PG} \\
\mathrm{E} 2 \mathrm{~L}\end{array}$ & & $\begin{array}{c}\mathrm{PG} \\
\mathrm{E} 1 \mathrm{~L} 2\end{array}$ & & $\begin{array}{l}\mathrm{PG} \\
\mathrm{E} 2 \mathrm{~L}\end{array}$ & & FF & & $\mathrm{AE}$ & & $\mathrm{AC}$ & & & \\
\hline$\overline{\text { FP101 x LF }}$ & 9,27 & $\mathrm{a}$ & 7,52 & $\mathrm{a}$ & 10,22 & $\mathrm{a}$ & 9,32 & $\mathrm{a}$ & 57,8 & $\mathrm{~b}$ & 134,1 & $\mathrm{~b}$ & 0,18 & $\mathrm{a}$ & 1,10 & $\mathrm{~b}$ \\
\hline FP109 x LF & 10,62 & $\mathrm{a}$ & 7,73 & $\mathrm{a}$ & 8,51 & $\mathrm{a}$ & 8,58 & $\mathrm{a}$ & 58,6 & b & 133,5 & b & 0,18 & $\mathrm{~b}$ & 1,28 & $\mathrm{a}$ \\
\hline FP004 x LD & 9,19 & $\mathrm{a}$ & 7,15 & $\mathrm{a}$ & 8,76 & $\mathrm{a}$ & 9,62 & $\mathrm{a}$ & 60,2 & $\mathrm{a}$ & 146,2 & $\mathrm{a}$ & 0,16 & $\mathrm{~b}$ & 1,05 & $\mathrm{c}$ \\
\hline FP022 x LD & 8,73 & $\mathrm{a}$ & 7,08 & $\mathrm{a}$ & 9,38 & $\mathrm{a}$ & 9,03 & $\mathrm{a}$ & 58,8 & b & 138,5 & $\mathrm{a}$ & 0,16 & $\mathrm{~b}$ & 1,07 & $\mathrm{~b}$ \\
\hline FP030 x LD & 7,70 & $\mathrm{a}$ & 8,99 & $\mathrm{a}$ & 8,37 & $\mathrm{a}$ & 8,79 & $\mathrm{a}$ & 57,6 & C & 137,2 & $\mathrm{a}$ & 0,13 & $\mathrm{~b}$ & 1,05 & $\mathrm{c}$ \\
\hline FP028 x LD & 9,06 & $\mathrm{a}$ & 6,85 & $\mathrm{a}$ & 9,24 & a & 8,47 & $\mathrm{a}$ & 58,5 & b & 132,3 & b & 0,12 & $\mathrm{~b}$ & 1,04 & $\mathrm{c}$ \\
\hline FP133 x LF & 8,84 & $\mathrm{a}$ & 7,16 & $\mathrm{a}$ & 8,29 & $\mathrm{a}$ & 9,27 & $\mathrm{a}$ & 57,9 & b & 133,8 & b & 0,11 & b & 1,08 & $\mathrm{~b}$ \\
\hline FP035 x LD & 8,48 & $\mathrm{a}$ & 7,69 & $\mathrm{a}$ & 8,47 & $\mathrm{a}$ & 8,90 & $\mathrm{a}$ & 59,7 & $\mathrm{a}$ & 144,1 & $\mathrm{a}$ & 0,12 & $\mathrm{~b}$ & 1,17 & $\mathrm{~b}$ \\
\hline FP032 x LD & 8,47 & $\mathrm{a}$ & 6,70 & $\mathrm{a}$ & 9,03 & $\mathrm{a}$ & 9,17 & $\mathrm{a}$ & 58,1 & b & 139,4 & $\mathrm{a}$ & 0,15 & $\mathrm{~b}$ & 1,07 & $\mathrm{c}$ \\
\hline FP005 x LD & 8,85 & $\mathrm{a}$ & 7,57 & $\mathrm{a}$ & 8,38 & $\mathrm{a}$ & 8,37 & $\mathrm{a}$ & 58,2 & b & 142,4 & $\mathrm{a}$ & 0,15 & $\mathrm{~b}$ & 1,02 & $\mathrm{c}$ \\
\hline FP104 x LF & 8,73 & $\mathrm{a}$ & 6,82 & $\mathrm{a}$ & 8,45 & $\mathrm{a}$ & 9,01 & $\mathrm{a}$ & 56,5 & d & 133,0 & b & 0,20 & $\mathrm{a}$ & 1,12 & $\mathrm{~b}$ \\
\hline FP026 x LD & 8,04 & $\mathrm{a}$ & 8,15 & $\mathrm{a}$ & 8,03 & $\mathrm{a}$ & 8,67 & $\mathrm{a}$ & 59,4 & $\mathrm{a}$ & 143,0 & $\mathrm{a}$ & 0,17 & $\mathrm{~b}$ & 1,16 & $\mathrm{~b}$ \\
\hline FP123 x LF & 7,92 & a & 7,37 & $\mathrm{a}$ & 8,88 & $\mathrm{a}$ & 8,69 & $\mathrm{a}$ & 57,9 & b & 128,4 & b & 0,26 & $\mathrm{a}$ & 1,12 & $\mathrm{~b}$ \\
\hline FP036 x LD & 9,41 & a & 5,98 & $\mathrm{a}$ & 8,95 & a & 8,48 & $\mathrm{a}$ & 57,9 & b & 131,9 & b & 0,14 & $\mathrm{~b}$ & 1,04 & $\mathrm{c}$ \\
\hline FP127 x LF & 8,82 & $\mathrm{a}$ & 6,72 & $\mathrm{a}$ & 8,50 & $\mathrm{a}$ & 9,72 & $\mathrm{a}$ & 56,8 & $\mathrm{~d}$ & 135,7 & $\mathrm{a}$ & 0,23 & $\mathrm{a}$ & 1,11 & $\mathrm{~b}$ \\
\hline FP120 x LF & 8,28 & a & 7,64 & $\mathrm{a}$ & 8,34 & $\mathrm{a}$ & 8,35 & $\mathrm{a}$ & 56,6 & d & 135,7 & $\mathrm{a}$ & 0,14 & b & 0,97 & $\mathrm{c}$ \\
\hline FP007 x LD & 8,01 & a & 7,81 & $\mathrm{a}$ & 8,16 & $\mathrm{a}$ & 8,35 & $\mathrm{a}$ & 58,7 & b & 146,4 & $\mathrm{a}$ & 0,19 & $\mathrm{a}$ & 1,06 & $\mathrm{c}$ \\
\hline FP112 x LF & 8,23 & $\mathrm{a}$ & 6,26 & $\mathrm{a}$ & 8,33 & $\mathrm{a}$ & 9,35 & $\mathrm{a}$ & 58,2 & b & 128,7 & b & 0,13 & $\mathrm{~b}$ & 1,08 & $\mathrm{~b}$ \\
\hline FP103 x LF & 6,76 & $\mathrm{a}$ & 8,12 & $\mathrm{a}$ & 8,44 & $\mathrm{a}$ & 8,85 & $\mathrm{a}$ & 57,3 & $\mathrm{C}$ & 130,4 & $b$ & 0,18 & $\mathrm{~b}$ & 1,06 & $\mathrm{c}$ \\
\hline FP021 x LD & 8,19 & $\mathrm{a}$ & 7,02 & $\mathrm{a}$ & 8,16 & $\mathrm{a}$ & 8,72 & $\mathrm{a}$ & 58,1 & b & 141,9 & $\mathrm{a}$ & 0,16 & $\mathrm{~b}$ & 1,07 & $\mathrm{~b}$ \\
\hline FP140 x LF & 7,35 & $a$ & 7,42 & $\mathrm{a}$ & 8,35 & $\mathrm{a}$ & 8,94 & $\mathrm{a}$ & 56,4 & d & 134,4 & b & 0,18 & $\mathrm{~b}$ & 1,06 & $\mathrm{c}$ \\
\hline FP029 x LD & 8,13 & $a$ & 7,44 & $\mathrm{a}$ & 8,11 & $\mathrm{a}$ & 8,24 & $\mathrm{a}$ & 58,1 & $b$ & 142,0 & $\mathrm{a}$ & 0,14 & $\mathrm{~b}$ & 1,05 & $\mathrm{c}$ \\
\hline FP019 x LD & 7,55 & a & 7,20 & $\mathrm{a}$ & 8,37 & $\mathrm{a}$ & 8,72 & $\mathrm{a}$ & 58,3 & b & 147,3 & $\mathrm{a}$ & 0,21 & $\mathrm{a}$ & 1,07 & $\mathrm{c}$ \\
\hline FP019 x LD & 8,88 & $\mathrm{a}$ & 5,37 & $\mathrm{a}$ & 8,73 & $\mathrm{a}$ & 8,62 & $\mathrm{a}$ & 58,0 & b & 136,2 & $\mathrm{a}$ & 0,12 & $\mathrm{~b}$ & 1,01 & $\mathrm{c}$ \\
\hline FP022 x LD & 7,53 & $\mathrm{a}$ & 5,66 & $\mathrm{a}$ & 8,92 & $\mathrm{a}$ & 9,32 & $\mathrm{a}$ & 58,7 & b & 146,2 & $\mathrm{a}$ & 0,25 & $\mathrm{a}$ & 1,05 & $\mathrm{c}$ \\
\hline FP023 x LD & 7,64 & $\mathrm{a}$ & 6,42 & $\mathrm{a}$ & 8,28 & $\mathrm{a}$ & 9,01 & $\mathrm{a}$ & 59,3 & $\mathrm{a}$ & 141,4 & $\mathrm{a}$ & 0,16 & $\mathrm{~b}$ & 1,01 & $\mathrm{c}$ \\
\hline FP015 x LD & 7,19 & a & 6,03 & $\mathrm{a}$ & 8,76 & $\mathrm{a}$ & 9,13 & $\mathrm{a}$ & 59,2 & $\mathrm{a}$ & 144,9 & $\mathrm{a}$ & 0,12 & $\mathrm{~b}$ & 1,08 & $\mathrm{~b}$ \\
\hline FP034 x LD & 7,19 & $\mathrm{a}$ & 6,90 & $\mathrm{a}$ & 8,59 & $\mathrm{a}$ & 8,27 & $\mathrm{a}$ & 58,5 & b & 135,0 & b & 0,27 & $\mathrm{a}$ & 1,06 & $\mathrm{c}$ \\
\hline FP037 x LD & 8,05 & $\mathrm{a}$ & 5,60 & $\mathrm{a}$ & 8,47 & $\mathrm{a}$ & 8,74 & $\mathrm{a}$ & 58,2 & b & 136,7 & $\mathrm{a}$ & 0,25 & $\mathrm{a}$ & 1,27 & $\mathrm{a}$ \\
\hline FP020 x LD & 7,45 & $\mathrm{a}$ & 6,18 & $\mathrm{a}$ & 8,50 & $\mathrm{a}$ & 8,37 & $\mathrm{a}$ & 58,2 & b & 134,6 & b & 0,11 & $\mathrm{~b}$ & 1,05 & $\mathrm{c}$ \\
\hline BRS1035 & 8,08 & $\mathrm{a}$ & 7,47 & $\mathrm{a}$ & 7,19 & $\mathrm{~b}$ & 7,42 & b & 57,2 & $\mathrm{c}$ & 131,2 & b & 0,10 & $\mathrm{~b}$ & 1,01 & $\mathrm{c}$ \\
\hline CFP & 7,57 & $\mathrm{a}$ & 4,65 & $\mathrm{a}$ & 6,50 & $\mathrm{~b}$ & 8,36 & $\mathrm{a}$ & 60,1 & $\mathrm{a}$ & 164,2 & $\mathrm{a}$ & 0,37 & $\mathrm{a}$ & 1,00 & $\mathrm{C}$ \\
\hline
\end{tabular}

* Médias seguidas da mesma letra não se diferenciam entre si de acordo com o agrupamento de Scott-Knot a 5\% de probabilidade. ${ }^{1}$ resultados grifados em cinza indicam tratamentos que tiveram desempenho superior 
condições em que foram feitas as avaliações, os pais recorrentes e as linhagens testadoras. A diferença entre as médias de produtividade de grãos dos compostos mancha-branca e ferrugem-polissora foi $0,70 \mathrm{tha}^{-}$ 1 , coincidente com a diferença entre média de produtividade de grãos dos dois grupos de ensaios, que foi de $0,71 \mathrm{tha}^{-1}$, o que sugere que em média os dois níveis de introgressão levaram a ganhos médios similares. Entretanto, é oportuno reforçar que a comparação direta das médias gerais entre esses dois conjuntos de ensaios deve ser vista com ressalvas, especialmente em razão das origens genéticas dos genitores doadores.

\section{Conclusão}

As famílias endogâmicas MB130, MB181, MB164, FP109, FP133, FP104, FP120, FP112, FP103 e FP140 apresentam potencial de uso no melhoramento em cruzamentos com linhagens do grupo heterótico duro, e as famílias endogâmicas MB024, MB032, MB083, FP028, FP036 e FP020, em cruzamentos com linhagens do grupo heterótico dentado.

\section{Referências}

ANDRADE, R. V.; SANTOS, M. X.; FERREIRA, A. S.; OLIVEIRA, A. C. Avaliação de acessos de milho crioulo coletados na região central do Brasil. Revista Brasileira de Milho e Sorgo, Sete Lagoas, v. 1, n. 2, p. 67-74, 2002. DOI: 10.18512/1980-6477/rbms.v1n2p67-74.

BRITO, A. H.; PINHO, R. G.; SANTOS, A. O.; SANTOS, S. Reação de híbridos de milho e comparação de métodos para avaliação da Cercosporiose e Mancha Branca. Tropical Plant Pathology, Brasília, DF, v. 36, n. 1, p. 35-41, 2011. DOI: $10.1590 /$ S1982-56762011000100005.

CASELA, C. R.; FERREIRA, A. S. Variability in isolates of Puccinia polysora in Brazil. Fitopatologia Brasileira,
Brasília, DF, v. 27, n. 4, p. 414-416, 2002.

DOI: $10.1590 / \mathrm{S} 0100-41582002000400015$.

COSTA, R. V.; CASELA, C. R.; COTA, L. V. Doenças. In: CRUZ, J. C. (Ed.). Cultivo do milho. 6. ed. Sete Lagoas: Embrapa Milho e Sorgo, 2010a.

COSTA, R. V.; COTA, L. V.; SILVA, D. D.; PARREIRA, D. F.; ROCHA, L. M. P.; GUIMARÃES, L. J. M.; GUIMARÃES, P. E.; PARENTONI, S. N.; MACHADO, J. R. A. Epidemias severas da ferrugem polissora do milho na região sul do Brasil na safra 2009/2010. Sete Lagoas: Embrapa Milho e Sorgo, 2010b. 6 p. (Embrapa Milho e Sorgo. Circular Técnica, 138).

COSTA, R. V.; COTA, L. V. Controle químico de doenças na cultura do milho: aspectos a serem considerados na tomada de decisão sobre a aplicação. Sete Lagoas: Embrapa Milho e Sorgo, 2009. 11 p. (Embrapa Milho e Sorgo. Circular Técnica, 125).

COSTA, R. V.; COTA, L. V.; SILVA, D. D.; LANZA, F. E. Recomendações para o controle químico da mancha branca do milho. Sete Lagoas: Embrapa Milho e Sorgo, 2011. 6 p. (Embrapa Milho e Sorgo. Circular Técnica, 167).

COSTA, R. V.; SILVA, D. D.; COTA, L. V. Reação de cultivares de milho à ferrugem polissora em casa de vegetação. Sete Lagoas: Embrapa Milho e Sorgo, 2015. 5 p. (Embrapa Milho e Sorgo. Circular Técnica, 214).

CRUZ, C. D. GENES: a software package for analysis in experimental statistics and quantitative genetics. Acta Scientiarum. Agronomy, Maringá, v. 35, n. 3, p. 271-276, 2013. DOI: 10.4025 /actasciagron.v35i3.21251.

FRITCHE-NETO, R.; VIEIRA, R. A.; SCAPIM, C. A.; MIRANDA, G. V.; REZENDE, L. M. Updating the ranking of the coefficients of variation from maize experiments. Acta Scientiarum. Agronomy, Maringá, v. 34, n. 1, p. 99 101, 2012.

DOI: 10.4025/actasciagron.v34i1.13115.

GODOY, C. V.; AMORIM, L.; BERGAMIN FILHO, A. Alterações na fotossíntese e na transpiração de folhas de 
milho infectadas por Phaeosphaeria maydis. Fitopatologia

Brasileira, Brasília, DF, v. 26, n. 2, p. 209-215, 2001.

DOI: $10.1590 / \mathrm{S} 0100-41582001000200017$.

GORJANC, G.; JENKO, J.; HEARNE, S. J.; HICKEY, J. $\mathrm{M}$. Initiating maize pre-breeding programs using genomic selection to harness polygenic variation from landrace population. Biomed Central Genomics, v. 13, p. 1-15, 2016. DOI: 10.1186/s12864-015-2345-Z.

MIRANDA FILHO, J. B.; NASS, L. L.; SANTOS, M. X.; REGITANO NETO, A. Avaliação de acessos de milho para resistência a doenças foliares. Brasília, DF: Embrapa Recursos Genéticos e Biotecnologia, 2000. 147 p.

NASS, L. L.; PATERNIANI, E. Pre-breeding: a link between genetic resources and maize breeding. Scientia Agricola, Piracicaba, v. 57, n. 3, p. 581-587, 2000. DOI: $10.1590 / \mathrm{S} 0103-90162000000300035$.

NASS, L. L.; NISHIKAWA, M. A. N.; FÁVERO, A. P.; LOPES, M. A. Pré-melhoramento de germoplasma vegetal. In: NASS, L. L. (Ed.). Recursos genéticos vegetais. Brasília, DF: Embrapa Recursos Genéticos e Biotecnologia, 2007. p. 683-716.

PACCOLA-MEIRELLES, L. D.; FERREIRA, A. S.; MEIRELLES W. F.; MARRIEL, I. E.; CASELA, C. R. Detection of a bacterium associated with a leaf spot disease of maize in Brazil. Journal of Phytophathology, Berlin, v. 149, n. 5 , p. 275-279, 2001.

DOI: 10.1046/j.1439-0434.2001.00614.x.

PARENTONI, S. N.; MAGALHÃES, J. V.; PACHECO, C. A. P.; SANTOS, M. X.; ABADIE, T.; GAMA, E. E. G.; GUIMARÃES, P. E. O.; MEIRELLES, W. F.; LOPES, M. A.; VASCONCELOS, M. J. V.; PAIVA, E. Heterotic groups based on yield-specific combining ability data and phylogenetic relationship by RAPD markers for 28 tropical maize open pollinated varieties. Euphytica, Wageningen, v. 121, n. 2, p. 197-208, 2001.

PATAKY, J. K.; NATTI, T. A.; SNYDER, E. B.; KUROWSKI, C. J. Puccinia sorghi in Sinaloa, Mexico virulent on corn with the Rp1-D gene. Plant Disease, Saint
Paul, v. 84, n. 7, p. 810, 2000.

DOI: 10.1094/PDIS.2000.84.7.810A.

PEREIRA FILHO, I. A.; BORGHI, E. Mercado de sementes de milho no Brasil safra 2016-2017. Sete Lagoas, Embrapa Milho e Sorgo, 2016. 33 p. (Embrapa Milho e Sorgo. Documentos, 202).

SANTOS, M. X.; POLLAK, L. M.; CARVALHO, H. W. L.; PACHECO, C. A. P.; GAMA, E. E. G.; GUIMARÃES, P. E. O.; ANDRADE, R. V. Heterotic responses of tropical elite maize accessions form Latino America with Brazilians testers. Scientia Agricola, Piracicaba, v. 58, n. 4, p. 767775, 2001. DOI: 10.1590/S0103-90162001000400019.

TEIXEIRA, F. F.; ANDRADE, R. V.; OLIVEIRA, A. C.; FERREIRA, A. S.; SANTOS, M. X. Diversidade no germoplasma de milho coletado na região nordeste do Brasil. Revista Brasileira de Milho e Sorgo, Sete Lagoas, v. 1, n. 3, p. 59-67, 2002.

DOI: 10.18512/1980-6477/rbms.v1n3p59-67.

TEIXEIRA, F. F.; COSTA, F. M.; SABATO, E. de O.; LEITE, C. E. P.; MEIRELLES, W. F.; GUIMARAES, C. T.; BELICUAS, S. N. J. Pré-melhoramento de milho quanto à resistência a enfezamentos. Pesquisa Agropecuária Brasileira, Brasília, DF, v. 48, n. 1, p. 51-58, 2013. DOI: $10.1590 / \mathrm{S} 0100-204 X 2013000100007$.

TEIXEIRA, F. F.; GOMIDE, R. L.; ALBUQUERQUE, P. E. P.; ANDRADE, C. T. L.; LEITE, C. E. P.; PARENTONI, S. N.; GUIMARÃES, P. E. O.; GUIMARÃES. L. J. M.; SILVA, A. R.; BASTOS, E. A.; CARDOSO, M. J. Evaluation of maize core collection for drought tolerance. Crop Breeding and Applied Biotechnology, Londrina, v. 10, n. 4, p. 312-320, 2010.

DOI: $10.1590 /$ S1984-70332010000400005.

TEIXEIRA, F. F.; GUIMARÃES, L. J. M.; GUIMARÃES, P. E. O.; PACHECO, C. A. P.; PARENTONI, S. N.; SILVA, A. R. Pré-melhoramento do milho. In: LOPES, M. A.; FÁVERO, A. P.; FERREIRA, M. A. J. F.; FALEIRO, F. G.; FOLLE, S. M.; GUIMARÃES, E. P. (Ed.). Prémelhoramento de plantas. Brasília, DF: Embrapa Informação Tecnológica, 2011. p. 571-614. 